\title{
Direct Torque and Frequency Control of Double-Inverter-Fed Slip-Ring Induction Motor Drive
}

\author{
Gautam Poddar and V. T. Ranganathan, Senior Member, IEEE
}

\begin{abstract}
A novel sensorless scheme for direct torque and frequency control of a double-inverter-fed slip-ring induction motor is presented. The analysis of a double-inverter-fed induction motor is given to derive the proposed controller. Various frequency profiles are analyzed for a direct frequency controller. A novel frequency profile is suggested to make the sensorless drive operation reliable and machine parameter independent at any rotor speed. Simulation and experimental results are presented from a 50-hp drive, demonstrating that the drive can deliver full torque from 0 to 2-p.u. speed in either direction. Thus, double the rated power can be extracted from the motor without overloading it.
\end{abstract}

Index Terms-Double inverter, sensorless control, slip-ring motor.

\section{NOMENCLATURE}

$L_{s}, L_{r} \quad$ Stator and rotor self inductances, respectively.

$L_{0} \quad$ Mutual inductance.

$\sigma_{s}, \sigma_{r} \quad$ Stator and rotor leakage factors.

$\sigma \quad$ Total leakage factor.

$R_{s}, R_{r} \quad$ Stator and rotor resistances, respectively.

$\bar{i}_{s} \quad$ Stator current vector in stationary reference frame.

$\bar{i}_{r} \quad$ Rotor current vector in rotor reference frame.

$\bar{V}_{s} \quad$ Stator voltage vector in stationary reference frame.

$\bar{V}_{r} \quad$ Rotor voltage vector in rotor reference frame.

$\omega_{s} \quad$ Stator supply frequency with respect to stationary frame.

$\omega_{r} \quad$ Rotor supply frequency with respect to rotor frame.

$\omega_{e} \quad$ Rotor speed in electrical radians per second.

\section{INTRODUCTION}

A grid-connected slip-ring induction motor with current injection on the rotor side can be operated in supersynchronous mode to produce up to two times the rated nominal power. The current injection can be achieved using either a cycloconverter [1] or back-to-back voltage-source inverters [2]. The grid-connected machine, however, is not capable of speed reversal without change of connections.

Manuscript received November 19, 2002; revised January 2, 2004. Abstract published on the Internet September 10, 2004. This work was supported by the Ministry of Information Technology, Government of India.

G. Poddar is with the Power Electronics Group, Electronics Research and Development Centre of India, Trivandrum 695 033, India (e-mail: gautam@erdcitvm.org).

V. T. Ranganathan is with the Electrical Engineering Department, Indian Institute of Science, Bangalore 560 012, India (e-mail: vtran@ee.iisc.ernet.in).

Digital Object Identifier 10.1109/TIE.2004.837897
A more versatile configuration is one where both the stator and the rotor of a slip-ring machine are fed from variable-frequency inverters. The resulting drive can operate in all four quadrants of the torque-speed plane [3]. The vector control scheme proposed by Kawabata et al. uses two separate torque current controllers for the stator and the rotor inverters. It is shown in the present work that the torque components of currents on the two sides are proportional to each other (5). Therefore, controlling them simultaneously but independently can lead to instability problems. Practically, during transient operation, the condition given in (5) cannot be met by using separate proportional-integral (PI) current controllers. Furthermore, the scheme requires operation of the inverters at very low fundamental frequency at some speeds of operation. It is also sensitive to machine parameters and exhibits excessive overshoot in the torque component of current during reversal. In [7], the authors of this paper demonstrated the sensorless vector control operation of this double-inverter-fed slip-ring drive with torque current control only from the stator side. A simple scalar $V / f$ control on the rotor side is proposed there. No abnormal rise in machine currents is noticed during all transient operations. However, this sensorless vector control scheme is dependent on the estimation of machine leakage parameters.

In this paper, a new scheme for direct torque and frequency control of the double-inverter-fed slip-ring induction motor is proposed. The scheme takes into account the proportionality between the torque current components on the two sides and thereby avoids instability problems in current control. By using novel frequency versus speed profiles for the two inverters, it is ensured that the fundamental frequency of operation on either side is always above a certain minimum value. This in turn means that simple sensorless schemes can be used for estimating the machine flux. The resulting control thus has very little dependence on machine parameters. However, a direct torque control (DTC) type of bang-bang control scheme does not ensure the constant inverter switching frequency unlike the sensorless vector control scheme presented in [7]. The proposed direct control scheme for torque and frequency enables fast dynamic control over the speed range of \pm 2 p.u., including zero speed. Results from simulation as well as an experimental 50-hp drive are presented to demonstrate the performance of the scheme.

Since the full torque can be obtained up to twice rated speed, the power output can be up to twice the rating of the machine. The drive is, therefore, an attractive alternative in high-power 
TABLE I

COMPARISON OF HIGH-POWER DRIVES USING VARIOUS MOTORS FOR A TYPICAL 1-MW RATING

\begin{tabular}{l|l|l|l|l|l}
\hline & Type of Drive & $\begin{array}{l}\text { Drive } \\
\text { Rating }\end{array}$ & $\begin{array}{l}\text { Motor } \\
\text { Rating }\end{array}$ & $\begin{array}{l}\text { Inverter } \\
\text { Rating }\end{array}$ & $\begin{array}{l}\text { Front-end } \\
\text { Converter } \\
\text { Diode } \\
\text { Rectifier } \\
\text { Rating }\end{array}$ \\
\hline 1. & $\begin{array}{l}\text { Squirrel-cage } \\
\text { induction motor } \\
\text { drive }\end{array}$ & $1 \mathrm{MW}$ & $1 \mathrm{MW}$ & $1 \mathrm{MW}$ & $1 \mathrm{MW}$ \\
\hline 2. & $\begin{array}{l}\text { Synchronous } \\
\text { Motor drive }\end{array}$ & $1 \mathrm{MW}$ & $1 \mathrm{MW}$ & $1 \mathrm{MW}$ & $1 \mathrm{MW}$ \\
\hline 3 & $\begin{array}{l}\text { Double inverter } \\
\text { Fed slip-ring } \\
\text { Induction motor } \\
\text { drive }\end{array}$ & $1 \mathrm{MW}$ & $0.5 \mathrm{MW}$ & $\begin{array}{l}0.5 \mathrm{MW} \\
+\end{array}$ & $1 \mathrm{MW}$ \\
\hline
\end{tabular}

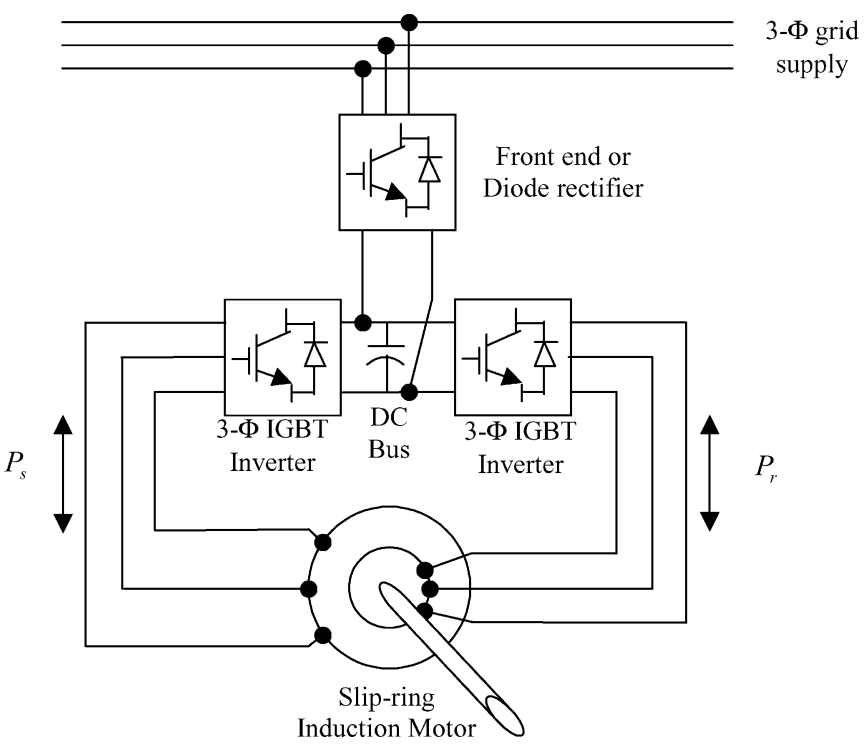

Fig. 1. Double-inverter-fed slip-ring induction motor drive.

applications to other schemes with complex topologies such as three-level inverters and cycloconverters. A comparison of highpower drives using various motors is given in Table I for a typical 1-MW rating to establish the advantage of this drive in terms of power ratings. The drives considered here are meant for variable-speed operation down to zero speed, with speed reversal. In applications where the speed range is limited and centered around the synchronous speed, the grid-connected slip-ring induction machine with rotor-side control [2] is the economical solution.

\section{FundAMENTALS OF BASIC CONFIGURATION}

The configuration of a double-inverter-fed induction motor drive is shown in Fig. 1. A three-phase insulated gate bipolar transistor (IGBT) inverter feeds power to the slip-ring induction motor through its stator terminals. Another three-phase inverter feeds power to the same motor through its rotor terminals. Both the inverters have a common dc bus. This dc bus is interfaced with the three-phase grid through a converter as in a conventional drive. If the regenerative braking is desired for high-power drives, then a front-end converter may be chosen between dc bus and the grid to deliver the regenerative power to the

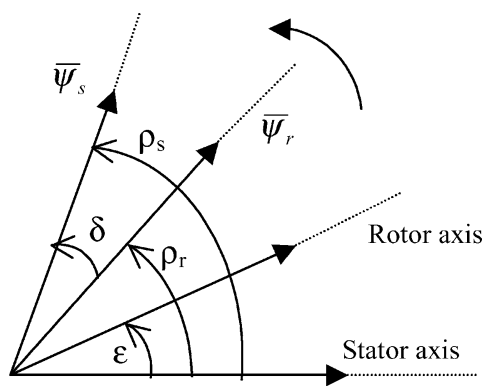

Fig. 2. Stator flux and rotor flux of the motor with respect to the rotor and the stator.

grid. Otherwise, a simple diode rectifier can be the cost-effective alternative to the sophisticated front-end converter. Unlike the grid-connected slip-ring motor drive with rotor-side control scheme [2], the front-end converter is not essential here. Now, the machine analysis is given to identify the control method suitable for this configuration.

\section{A. Machine Torque and Torque Current}

At any instant of time, the stator flux vector, rotor flux vector, and the rotor position are shown in Fig. 2 with respect to the stator axis. The equation of the stator flux in the stator coordinate system is

$$
\bar{\psi}_{s}=L_{s} \bar{i}_{s}+L_{0} \bar{i}_{r} e^{j \varepsilon}=\int\left(\bar{V}_{s}-R_{s} \bar{i}_{s}\right) d t .
$$

The air-gap flux in the stator coordinate is

$$
\bar{\psi}_{m}=L_{0} \bar{i}_{s}+L_{0} \bar{i}_{r} e^{j \varepsilon}
$$

and the rotor flux equation in the rotor coordinates is

$$
\bar{\psi}_{r}=L_{r} \bar{i}_{r}+L_{0} \bar{i}_{s} e^{-j \varepsilon}=\int\left(\bar{V}_{r}-\bar{i}_{r} R_{r}\right) d t .
$$

The developed electromagnetic torque of the machine is

$$
m_{d}=\frac{2}{3} L_{0} \operatorname{Im}\left[\bar{i}_{s}\left(\bar{i}_{r} e^{j \varepsilon}\right)^{*}\right] .
$$

Therefore, the torque is proportional to the vector product of two currents $\left(\bar{i}_{s}, \bar{i}_{r} e^{j \varepsilon}\right)$. Now, both these currents are resolved along the air-gap flux $\left(\bar{\psi}_{m}\right)$ axis as shown in Fig. 3. The following results are obtained:

$$
\begin{aligned}
i_{s q} & =-i_{r q} \\
m_{d} & =\frac{2}{3} \psi_{m} i_{s q} .
\end{aligned}
$$

From the above equations, it is clear that the quadrature-axis stator current $i_{s q}$ generates the machine torque. The rotor quadrature-axis current $i_{r q}$ is developed automatically as the reflection of $i_{s q}$. Hence, the machine torque is required to be controlled only from one side, for example, the stator side.

From (1), (3), and (4), the electromagnetic torque can be rewritten as

$$
m_{d}=\frac{2}{3} \frac{L_{0}}{\sigma L_{r} L_{s}} \operatorname{Im}\left[\bar{\psi}_{s}\left(\bar{\psi}_{r}^{j \varepsilon}\right)^{*}\right] .
$$

The above equation shows that the electromagnetic torque is also the cross product of the stator and rotor fluxes, i.e., the 


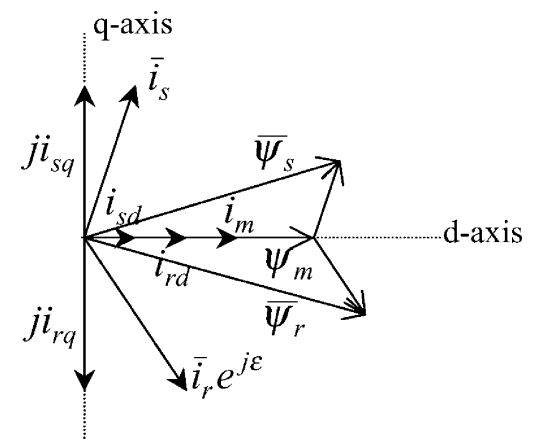

Fig. 3. Phasor diagram of machine fluxes and currents with air-gap flux orientation.

product of $\psi_{r}, \psi_{s}$, and the sine of angle $\delta$ between two fluxes (Fig. 2). Therefore, the controlled variations of the angle $\delta$ control the machine torque directly and the torque current indirectly.

\section{B. Machine Fluxes and Sharing of Magnetizing Current}

The rotor flux magnitude $\left(\psi_{r}\right)$ and the stator flux magnitude $\left(\psi_{s}\right)$ control the air-gap flux magnitude $\left(\psi_{m}\right)$ as follows.

Applying air-gap flux orientation on machine flux (1)-(3),

$$
\begin{aligned}
& \psi_{m}=L_{0} i_{m}=L_{0}\left(i_{s d}+i_{r d}\right) \\
& \psi_{s d}=L_{s} i_{s d}+L_{0} i_{r d} \\
& \psi_{r d}=L_{r} i_{r d}+L_{0} i_{s d} \\
& \psi_{r q}=\sigma_{r} L_{0} i_{r q} \\
& \psi_{s q}=-\sigma_{s} L_{0} i_{r q} .
\end{aligned}
$$

Solving (9) and (10), we get

$$
\begin{aligned}
i_{s d} & =\frac{\psi_{s d}}{\sigma L_{s}}-\frac{1-\sigma}{\sigma} \frac{\psi_{r d}}{L_{0}} \\
i_{r d} & =\frac{\psi_{r d}}{\sigma L_{r}}-\frac{1-\sigma}{\sigma} \frac{\psi_{s d}}{L_{0}} .
\end{aligned}
$$

From (8), it is seen that the air-gap flux magnitude $\left(\psi_{m}\right)$ is constant as long as $\left(i_{s d}+i_{r d}\right)$ is constant. Equations (13) and (14) state that $i_{s d}$ and $i_{r d}$ depend on $d$-axis stator flux $\left(\psi_{s d}\right)$ and $d$-axis rotor flux $\left(\psi_{r d}\right)$ completely. At no load, $q$-axis fluxes on both sides $\left(\psi_{s q}, \psi_{r q}\right)$ become zero [see (11) and (12))]. Therefore, at that condition, the stator flux magnitude $\psi_{s}$ equals the $d$-axis flux $\psi_{s d}$ and the rotor flux magnitude $\psi_{r}$ equals the $d$-axis flux $\psi_{r d}$. The proper values of $\psi_{s}$ and $\psi_{r}$ references can produce definite values of $i_{s d}, i_{r d}$, and the net magnetizing current $i_{m}$ in the machine [see (8), (13), and (14)]. Thus, the selection of $\psi_{s}$ and $\psi_{r}$ references can control the sharing of magnetizing current between the stator winding and the rotor winding of the machine.

However, with load, the $q$-axis fluxes $\left(\psi_{s q}, \psi_{r q}\right)$ on both sides of the machine become nonzero. Now, if the stator and the rotor fluxes $\left(\psi_{s}, \psi_{r}\right)$ are kept constant, then using (11) and (12), $d$-axis fluxes can be written as

$$
\begin{aligned}
& \psi_{s d}=\sqrt{\psi_{s}^{2}-\psi_{s q}^{2}}=\psi_{s} \sqrt{1-\left(\frac{\sigma_{s} L_{0} i_{r q}}{\psi_{s}}\right)^{2}} \\
& \psi_{r d}=\sqrt{\psi_{r}^{2}-\psi_{r q}^{2}}=\psi_{r} \sqrt{1-\left(\frac{\sigma_{r} L_{0} i_{r q}}{\psi_{r}}\right)^{2}} .
\end{aligned}
$$

The above equations show that there are changes in values of $d$-axis fluxes from no load to full load. This leads to changes in $i_{s d}, i_{r d}$, and $\psi_{m}$ [see (8), (13), and (14)]. However, for practical machines, the leakage factors $\sigma_{r}$ and $\sigma_{s}$ are very small. Assuming rated constant flux magnitudes for $\psi_{s}$ and $\psi_{r}$, the variations of $d$-axis flux magnitudes from no load to full load will be less than $5 \%$. Hence, the choice of $\psi_{s}$ and $\psi_{r}$ can determine the magnetizing current and the sharing of magnetizing current completely.

\section{Proposed Control Method}

The block diagram of the proposed controller is shown in Fig. 4.

\section{A. Stator-Side Controller}

As mentioned earlier, there is a torque controller to control the stator-side inverter. The algorithm is based on DTC [4]-[6]. In this method, the electromagnetic torque $\left(m_{d}\right)$ of the machine is derived from the stator flux $\left(\bar{\psi}_{s}\right)$ and the stator currents $\left(\bar{i}_{s}\right)$ as follows.

From (1) and (4), the machine torque can be rewritten as

$$
m_{d}=\frac{2}{3} \operatorname{Im}\left[\bar{i}_{s} \bar{\psi}_{s}^{*}\right]=\frac{2}{3}\left(\psi_{s \alpha} i_{s \beta}-\psi_{s \beta} i_{s \alpha}\right) .
$$

Now, from (1), $\psi_{s \alpha}$ and $\psi_{s \beta}$ in the $\alpha-\beta$ frame of stationary coordinates are derived as follows:

$$
\begin{aligned}
\psi_{s \alpha} & =\int\left(V_{s \alpha}-R_{s} i_{s \alpha}\right) d t \\
\psi_{s \beta} & =\int\left(V_{s \beta}-R_{s} i_{s \beta}\right) d t \\
\psi_{s} & =\sqrt{\psi_{s \alpha}^{2}+\psi_{s \beta}^{2}} .
\end{aligned}
$$

The stator voltages $V_{s \alpha}$ and $V_{s \beta}$ in the $\alpha-\beta$ frame are calculated based on the measurements of dc-bus voltage and the switching states of the inverter. To represent the switching state of the inverter (Fig. 5), the switching function $S_{1 s}$ for phase lis defined as follows: $S_{1 s}=1$ when the upper switch of phase 1 is on and $S_{1 s}=0$ when the lower switch of phase 1 is on. Similar definitions can be made for phases 2 and 3. Now, the voltage equations are

$$
\begin{aligned}
V_{s \alpha} & =V_{\mathrm{dc}}\left(S_{1 s}-\frac{S_{2 s}}{2}-\frac{S_{3 s}}{2}\right) \\
V_{s \beta} & =\frac{\sqrt{3}}{2} V_{\mathrm{dc}}\left(S_{1 s}-S_{2 s}\right) .
\end{aligned}
$$

The stator line currents are expressed in the $\alpha-\beta$ frame as follows:

$$
\begin{aligned}
i_{s \alpha} & =\frac{3}{2} i_{1 s 1} \\
i_{s \beta} & =\frac{\sqrt{3}}{2}\left(i_{s 2}-i_{s 3}\right) .
\end{aligned}
$$

Now, the stator flux angular velocity is obtained from the following equation:

$$
\omega_{s}=\frac{\left(V_{s \beta}-i_{s \beta} R_{s}\right) \psi_{s \alpha}-\left(V_{s \alpha}-i_{s \alpha} R_{s}\right) \psi_{s \beta}}{\psi_{s \alpha}^{2}+\psi_{s \beta}^{2}} .
$$




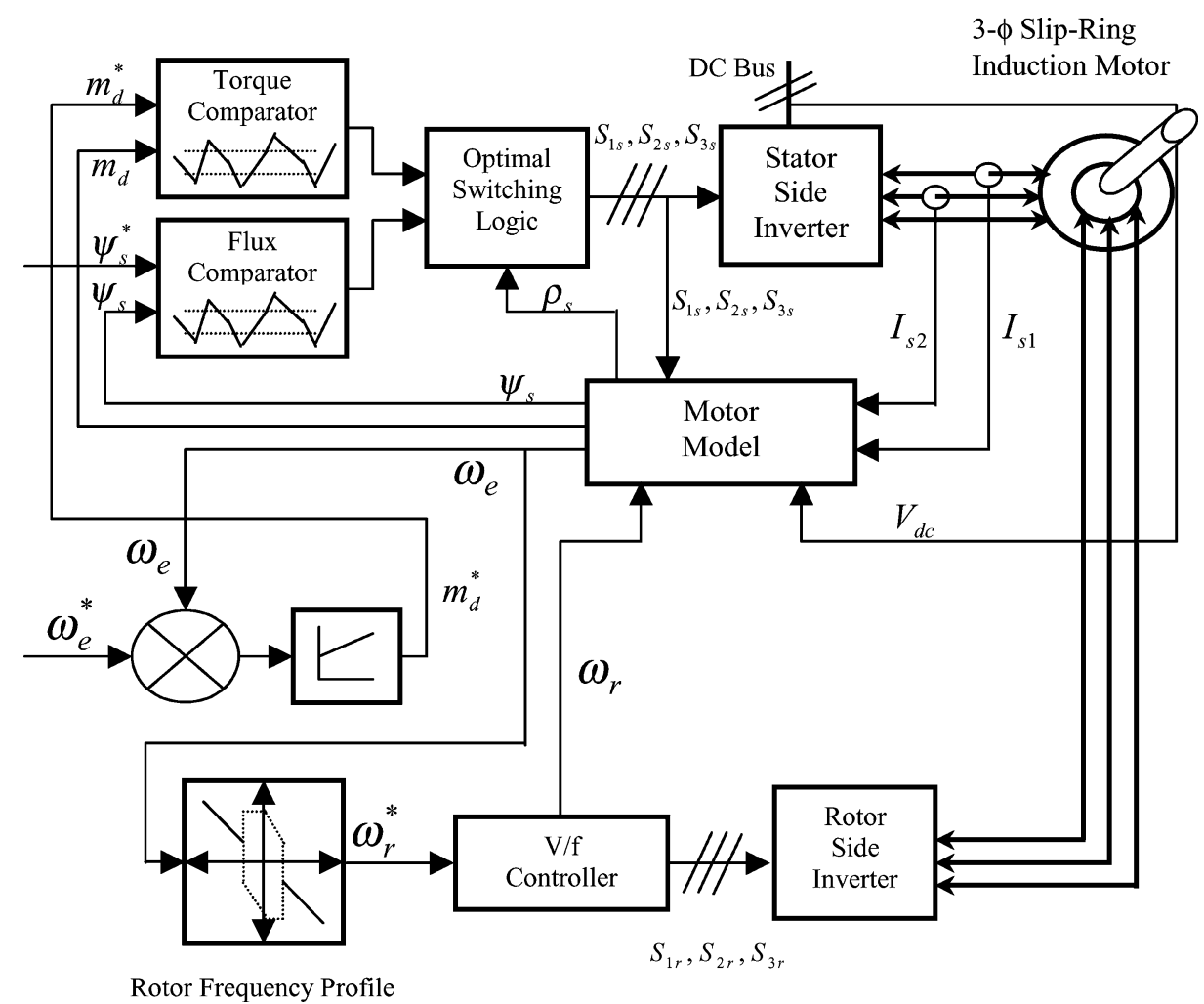

Fig. 4. Overall block diagram of the controller.

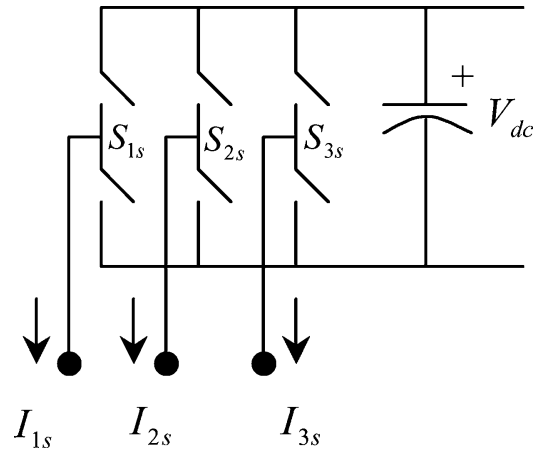

Fig. 5. Typical voltage-source inverter.

Therefore, the stator flux position $\rho_{s}$ is derived as

$$
\rho_{s}=\int \omega_{s} d t
$$

There are eight voltage vectors $\left(\bar{V}_{i}\left(S_{1 s}, S_{2 s}, S_{3 s}\right)\right.$, $i=0,1, \ldots 7 \cdot)$ available for the voltage-source inverter. They are shown in Fig. 6 in the $\alpha-\beta$ stationary coordinate system. Among them, there are six nonzero voltage vectors $\left(\bar{V}_{i}\left(S_{1 s}, S_{2 s}, S_{3 s}\right), i=1,2, \ldots 6 \cdot\right)$ and two zero voltage vectors $\left(\bar{V}_{i}\left(S_{1 s}, S_{2 s}, S_{3 s}\right), i=0,7 \cdot\right)$. When one of six active voltage vectors is chosen for the inverter, then the end of $\bar{\psi}_{s}$ moves parallel to the voltage vector $\bar{V}_{i}$ chosen. On the other hand, the null vectors stop the flux, whenever they are applied to the inverter. By selecting appropriate voltage vector $\bar{V}_{i}$, the end of $\bar{\psi}_{s}$ rotates at the frequency $\omega_{s}$ along the zigzag line shown in Fig. 6. However, the average locus of $\bar{\psi}_{s}$ is circular, as shown by the dotted line in Fig. 6 .

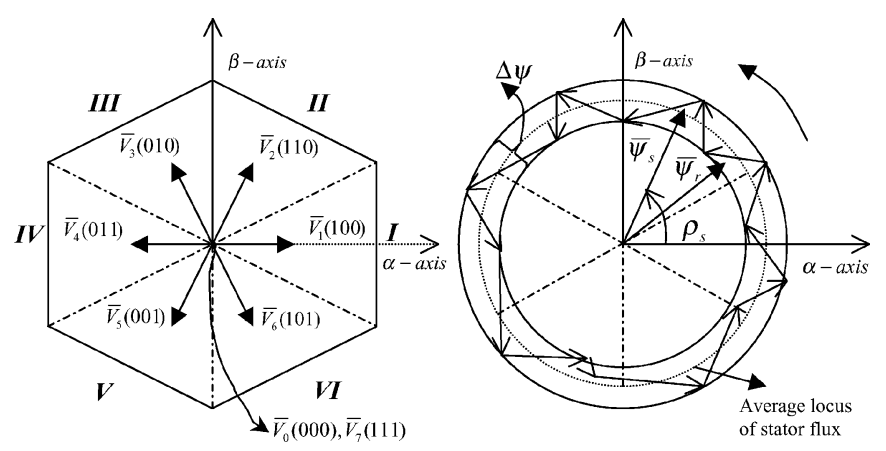

Fig. 6. Different inverter voltage vectors and the flux path on $\alpha-\beta$ frame.

To get the correct voltage vector at each instant, the following method is adopted. The $\alpha-\beta$ plane is divided into six sectors. At every instant, $\rho_{s}$ is estimated using (21) to get the sector number that contains the stator flux at that moment. For example, in Fig. 6 the stator flux lies on the sector number II and rotates in the anticlockwise direction. The rotor flux $\bar{\psi}_{r}$ trails the stator flux. If it is required to increase the torque, the stator flux has to be accelerated to increase the angle between the stator flux and the rotor flux as explained earlier [see (7)]. Therefore, the voltage vector $\bar{V}_{3}$ or $\bar{V}_{4}$ can be selected. Now, if the stator flux magnitude has to be increased, then the voltage vector $\bar{V}_{3}$ has to be selected for the inverter. Otherwise, $\bar{V}_{4}$ has to be selected. Similarly, to decrease the torque, $\bar{V}_{1}$ or $\bar{V}_{6}$ can be selected. The flux magnitude error will decide the final voltage vector uniquely among those two voltage vectors. For other sectors the unique voltage vector can also be selected at each instant on the basis of torque error and the flux error. 


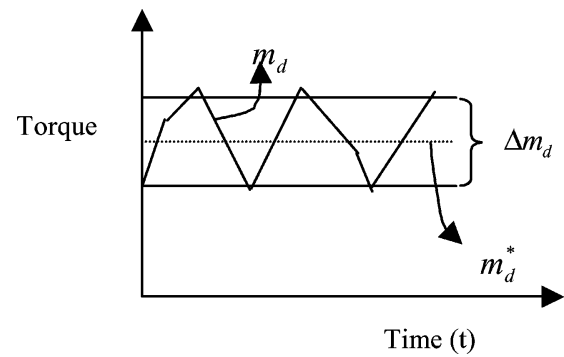

Fig. 7. Bang-bang torque control.

The null vector should be used here carefully. It stops the stator flux and holds the flux magnitude constant. During motoring operation, the stator flux leads the rotor flux as shown in Fig. 6. During this operation if the null vector is applied to the motor, the stator flux stops and the rotor flux continues to move toward the stator flux. The torque angle $\delta$ (Fig. 2) starts collapsing, which reduces the torque magnitude gradually. However, during regeneration, the rotor flux leads the stator flux. Now, if the stator flux is stopped using the null vector, the rotor flux moves away from the stator flux. As a result, the torque angle $\delta$ starts increasing and the torque magnitude also increases gradually.

Finally, the stator-side controller is developed with the following modules. It has a PI controller to control the rotor speed $\left(\omega_{e}\right)$ to the reference value $\left(\omega_{e}^{*}\right)$. The rotor speed is estimated from the rotor frequency $\left(\omega_{r}\right)$ and the stator frequency $\left(\omega_{s}\right)$ as follows:

$$
\omega_{e}=\omega_{s}-\omega_{r}
$$

The output of the speed controller is the torque reference $\left(m_{d}^{*}\right)$ of the machine. Using (16), the actual machine torque $\left(m_{d}\right)$ is estimated and compared with the torque reference to get the torque error. The stator flux magnitude reference $\left(\psi_{s}^{*}\right)$ can be chosen on the basis of rated flux of the machine and the sharing of magnetizing current by the stator-side inverter ((8), (13) and (14)). The stator flux magnitude $\left(\psi_{s}\right)$ is estimated from (17) and compared with the reference flux to estimate the flux error. As mentioned earlier, the torque error and the flux error are the basis of selection of proper voltage vectors to reduce the errors. Thus, the flux and the torque controllers are of the bang-bang type.

To control the switching frequency of the inverter, there is a small flux band $(\Delta \psi)$ and a torque band $\left(\Delta m_{d}\right)$ as shown in Figs. 6 and 7. When the torque error and the flux error are within those bands, there is no change in voltage vector selection for the inverter. Whenever the error crosses the band, an updated voltage vector is applied to the motor to reduce the error. Thus, the actual torque and flux are made to follow the respective reference values. By setting the proper torque and flux error bandwidth, the inverter switching frequency can be controlled within the safe limit of the switching devices.

\section{B. Rotor-Side Controller}

As mentioned earlier, the stator-side torque controller controls the torque current on the rotor side. So, there is no need for a separate torque or torque current controller on the rotor side. However, the rotor flux magnitude $\left(\psi_{r}\right)$ determines the sharing of magnetizing current by the rotor-side inverter. Therefore, flux control is required to control the sharing of magnetizing current between the two sides.

A constant $V / f$ type pulsewidth-modulation (PWM) controller is used to keep the rotor flux $\left(\psi_{r}\right)$ approximately constant to its reference value. Here, also, (8), (13), and (14) are used to determine the rotor flux reference, i.e., $V / f$ ratio. At any particular rotor speed $\left(\omega_{e}\right)$, the constant $V / f$-type PWM controller directly controls the rotor flux angular velocity $\left(\omega_{r}\right)$. The corresponding stator flux angular velocity $\left(\omega_{s}\right)$ has a unique value conforming to (22). So, this method of rotor-side control is termed as direct frequency control.

\section{Frequency Command Generation for Rotor-Side Controller}

From (22) it can be seen that for any particular rotor speed $\left(\omega_{e}\right)$, there are infinite combinations of stator flux frequency $\left(\omega_{s}\right)$ and the rotor flux frequency $\left(\omega_{r}\right)$ possible. Here, the rotor flux frequency is varied directly in open loop. Since the direct torque controller forces the stator flux to follow the rotor flux closely, the stator flux frequency is automatically established obeying (22). The direct rotor flux frequency command $\left(\omega_{r}^{*}\right)$ is chosen in such a way that the rotor flux and/or stator flux do not rotate at very low frequency at any rotor speed $\left(\omega_{e}\right)$. At very low rotor flux frequency, it is very difficult to maintain the rotor flux $\psi_{r}$ constant by simply keeping the $V / f$ ratio constant. At very low stator frequency, the DTC algorithm also fails due to the drifting of pure integrator and the inaccurate estimation of stator resistance drop.

Therefore, several rotor flux frequency command profiles are developed to limit the lowest frequency on either side of the motor to $12 \mathrm{~Hz}$ (for a $50-\mathrm{Hz}$ machine) at all operating conditions. One of these profiles is presented in this paper. This proposed rotor flux frequency command $\left(\omega_{r}^{*}\right)$ is shown as a function of estimated rotor speed $\left(\omega_{e}\right)$ in Fig. 8. Fig. 9 shows the corresponding stator flux frequency. It is clear from Figs. 8 and 9 that the stator flux and the rotor flux always rotate above $25 \%$ of the rated frequency. As mentioned earlier, the stator flux frequency is developed automatically by the torque control process, whereas the PWM controller develops the rotor flux frequency directly.

There are some frequency-reference jumps around the rotor speed $30 \mathrm{~Hz}$. They do not lead to any current overshoots in the motor as long as the stator-side current control (torque control) is very fast. This is ensured by the DTC on the stator side. For rotor speeds above $35 \mathrm{~Hz}$, the rotor flux frequency command follows the following equation:

$$
\omega_{r}^{*}=-\frac{\omega_{e}}{2} .
$$

Below $30-\mathrm{Hz}$ rotor speed, the rotor flux frequency command can follow either of two profiles as shown in Fig. 8. In one part of the profile, the rotor flux frequency command is kept constant at $47 \mathrm{~Hz}$ for a particular direction of rotor speed. In the other direction of rotation, the rotor flux frequency command is generated from the following equation:

$$
\omega_{r}^{*}=2 \pi \times 47-\omega_{e} .
$$

The rotor flux frequency command profile forms a hysterisis loop at low rotor speed. 


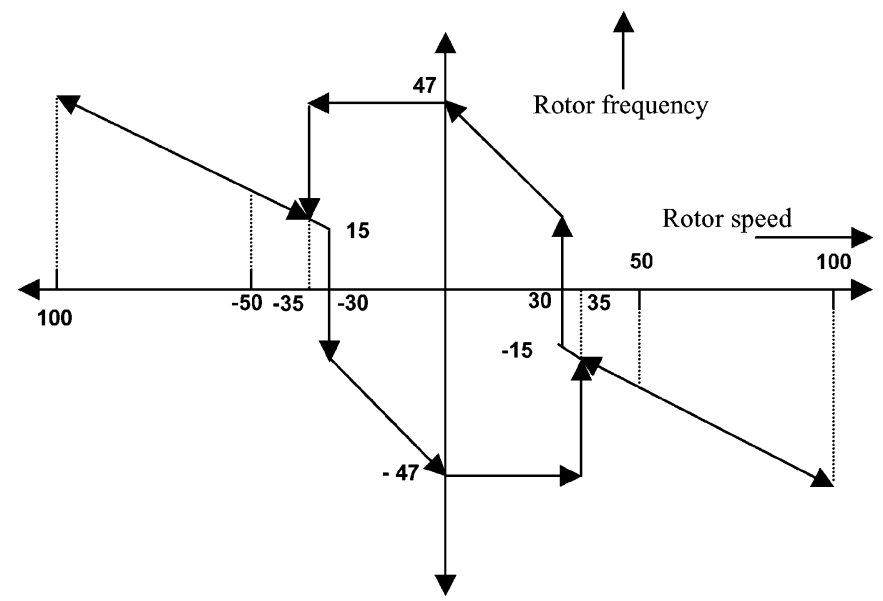

Fig. 8. Rotor frequency command versus rotor speed.

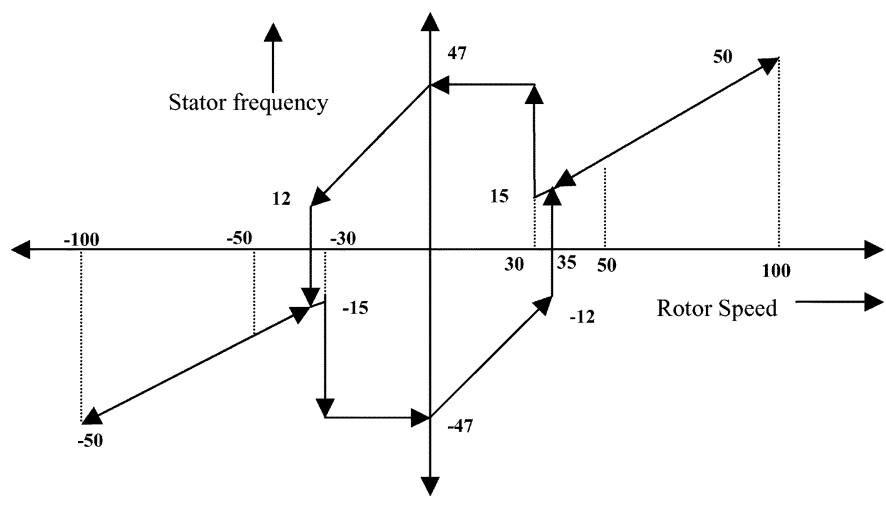

Fig. 9. Stator frequency versus rotor speed.

A 5-Hz rotor speed band (from 30 to $35 \mathrm{~Hz}$ ) is provided in the rotor flux frequency command profile to avoid the rotor frequency jittering during the frequency jumps.

The frequency profiles shown are interchangeable, i.e., the given stator flux frequency plot can be used as a rotor flux frequency command. Then, the generated stator flux frequency plot will be the present rotor flux frequency command.

\section{Power Flow From Stator and Rotor}

There are two definite operating regions for the frequency profiles presented in this paper. One is for operation at rotor speeds below $30 \mathrm{~Hz}$ and the other is for operation at rotor speeds above $35 \mathrm{~Hz}$. For rotor speeds above $35 \mathrm{~Hz}$, the rotor flux frequency and the stator flux frequency have equal magnitude, but opposite sign. Under this condition, the power flow from the stator and the rotor can be analyzed as follows.

Assume that the power fed from the stator-side inverter to the machine is $P_{s}$. The power fed from the rotor-side inverter to the machine is $P_{r}$ and the output electrical power from the machine is $P_{e}$. For any arbitrary constant load torque $m_{d}, P_{s}$ and $P_{r}$ can be written from (5) and (6) as

$$
\begin{aligned}
& P_{s}=m_{d} \omega_{s} \\
& P_{r}=\left(-m_{d}\right) \omega_{r} .
\end{aligned}
$$

Now, from (22) and (23), it is seen that

$$
\omega_{s}=-\omega_{r}=\frac{\omega_{e}}{2}
$$

the sign of $P_{s}$ and $P_{r}$ are the same, i.e., during motoring operation of the machine, both the stator inverter and the rotor inverter feed the power to the machine. On the other hand, during regeneration, both inverters draw power from the machine and feed it to the common dc bus. This is called supersynchronous operation of the machine.

Now, each 1-p.u. inverter is capable of producing rated torque $\left(m_{\text {rated }}\right)$ at rated frequency $\left(\omega_{\text {rated }}\right)$. When these inverters operate at a condition conforming to (26), the net output power developed from the machine is

$$
P_{e}=P_{s}+P_{r}=2 \omega_{\text {rated }} m_{\text {rated }} .
$$

Therefore, the motor output power becomes twice the rated power. This is a very attractive advantage of this drive for high-power applications. At this condition, the rotor speed $\left(\omega_{e}\right)$ becomes twice the rated speed [see (26)].

For rotor speeds below $30 \mathrm{~Hz}$, the rotor flux frequency $\omega_{r}$ and the stator flux frequency $\omega_{s}$ have the same sign. However, their magnitudes are different. Therefroe, from (25), it is clear that $P_{s}$ and $P_{r}$ have the opposite sign. During motoring operation, the stator-side inverter feeds power to the machine (25) when $\left|\omega_{s}\right|>\left|\omega_{r}\right|$. At this condition, the rotor-side inverter draws power from the machine and feeds it back to the common dc bus (25). The balance power is equal to the net output power from the machine $\left(P_{e}\right)$. For any given load torque $m_{d}$,

$$
P_{e}=m_{d}\left(\omega_{s}-\omega_{r}\right) .
$$

On the contrary, the stator-side inverter draws power in excess from the machine and feeds it to the dc bus during regeneration when $\left|\omega_{s}\right|>\left|\omega_{r}\right|$. At this condition, the rotor-side inverter draws power from the dc bus and feeds it to the machine. The balance power is again equal to the net electrical power $\left(P_{e}\right)$ of the machine.

Therefore, there is always a circulation of power from the stator to the rotor through the machine or vice versa. This is called the subsynchronous operation of the machine.

\section{Simulation Results}

Simulation results based on direct torque and direct frequency control are shown in Figs. 10 and 11. The results prove the feasibility of the algorithm proposed here. They show the firm torque and current control during the step change of the speed command. In Figs. 10 and 11, the currents shown are equivalent two-phase currents (i.e., 1.5 times actual three-phase currents). They also show the stable sensorless zero rotor speed operation with stator- and rotor-side inverters running at nonzero frequency.

\section{EXPERIMENTAL RESULTS}

The experimental verification is carried out on a 50-hp slipring induction motor. Both the stator and the rotor are fed by three-phase IGBT inverters. The average switching frequency 

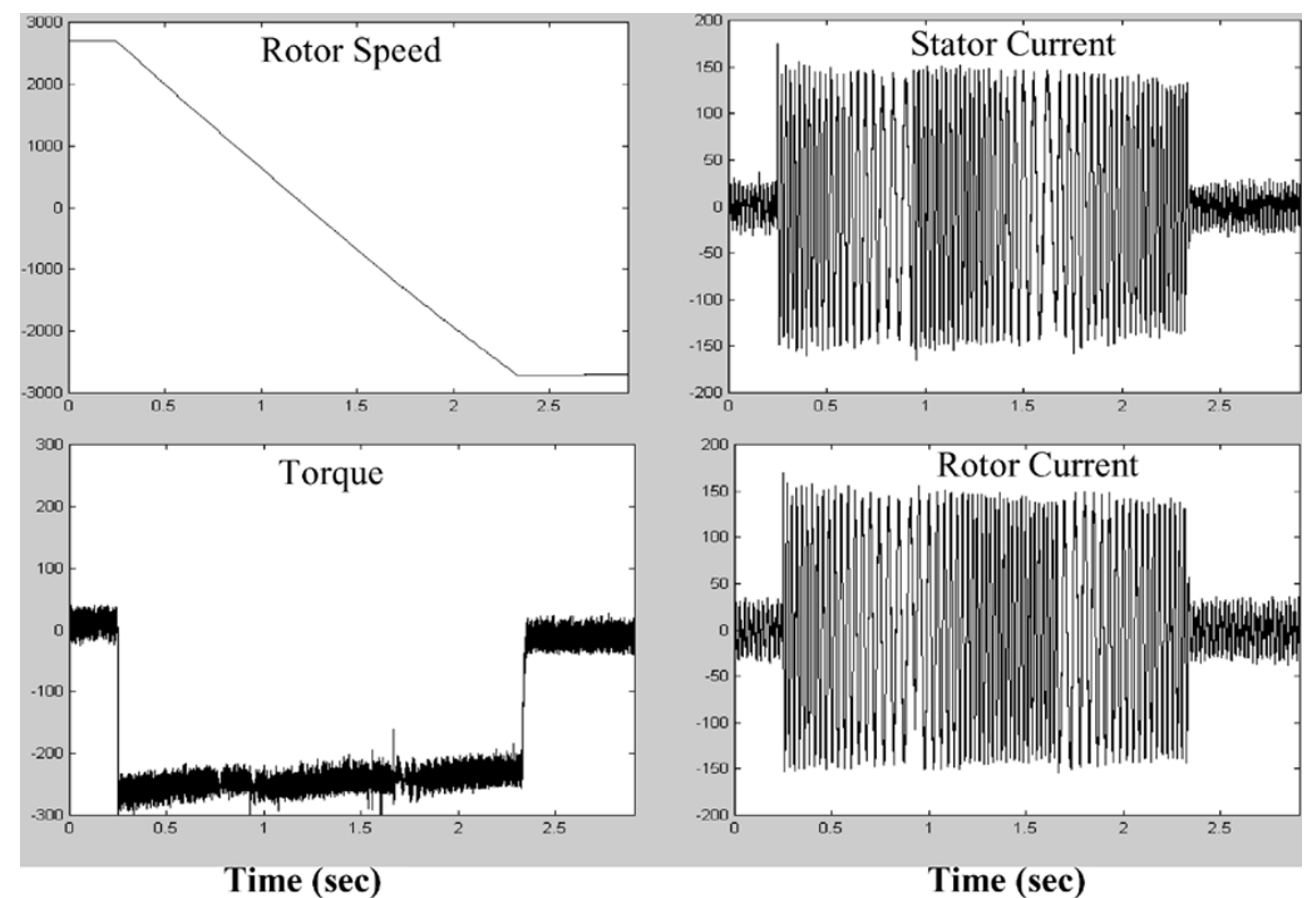

Fig. 10. Simulated operation during sudden speed reversal.

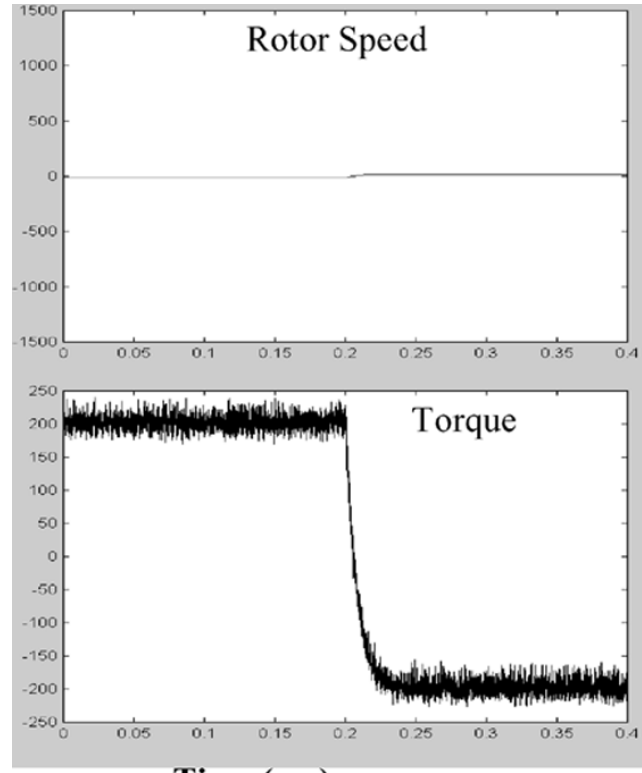

Time (sec)
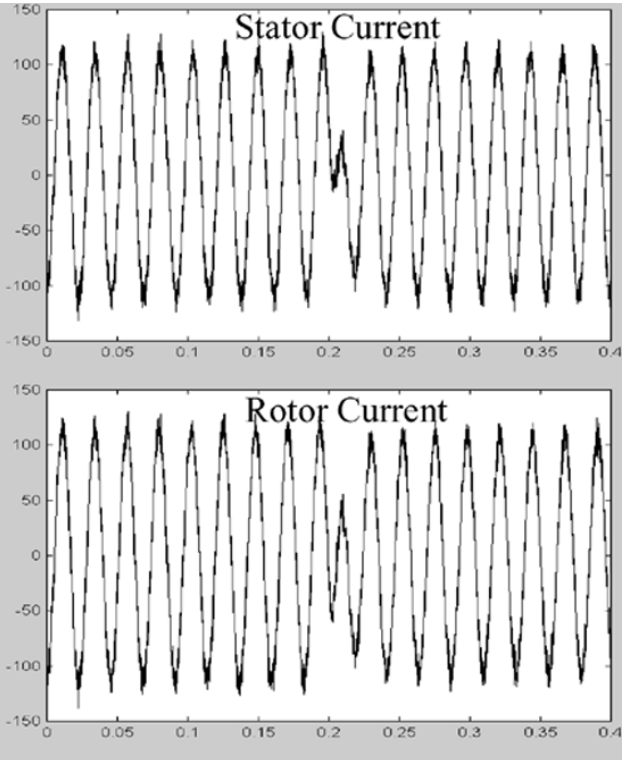

Time (sec)

Fig. 11. Simulated operation during sudden torque reversal at zero speed.

of the inverters is $1.5 \mathrm{kHz}$. A common de bus $(600 \mathrm{~V})$ supplies power to both inverters. A digital-signal-processor (DSP)-based controller carries out the control of the inverters. A $40-\mathrm{MHz}$ clock drives the processor. The program runs from the on-chip RAM area. This DSP communicates with a supervisory microcontroller through a dual-port RAM (DPRAM). There are two LEM current sensors to measure the stator-side line currents and another set of two line current sensors for the rotor-side line currents. There is a voltage sensor to measure the dc-bus voltage. The motor line voltages of the stator and the rotor terminals are estimated from this measured dc-bus voltage and the switching states of the inverters.
The program is written in assembly language. The control cycle time is set at $60 \mu \mathrm{s}$. The stator-side inverter is controlled by the DTC method. The rotor-side inverter is controlled by the direct frequency control method. The experimental waveforms are shown in Figs. 12-18. Fig. 12 shows the torque waveform and the rotor speed waveform for a step change in speed reference. It experimentally verifies that, even at $150 \%$ of rated speed, the full torque of the machine is developed. This confirms the extra power available from the machine due to the proposed controller. Figs. 13 and 14 show the stator and the rotor current waveforms when the rotor speed is ramped up to twice the rated speed. Fig. 15 shows the machine current wave- 


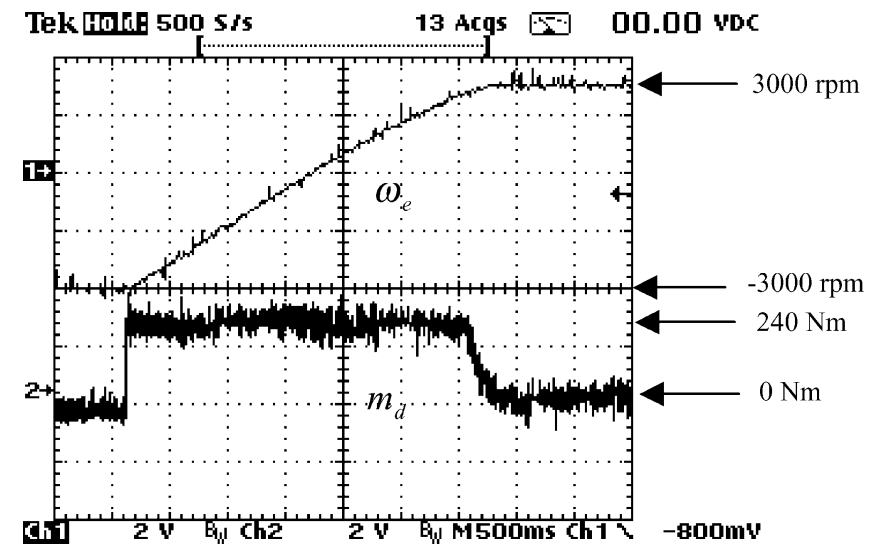

Fig. 12. Experimental waveform of sudden speed reversal. 1 p.u. speed $=$ $1500 \mathrm{r} / \mathrm{min}, 1$ p.u. torque $=240 \mathrm{~N} \cdot \mathrm{m}$.

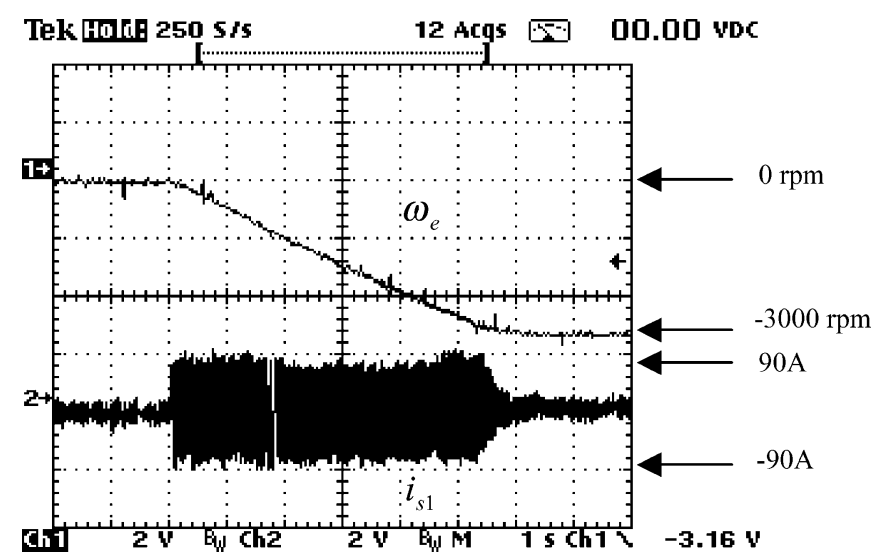

Fig. 13. Experimental waveform of stator current during speed transient. 1 p.u. speed $=1500 \mathrm{r} / \mathrm{min}, 1$ p.u. current $=63.7 \mathrm{~A}(\mathrm{rms})$.

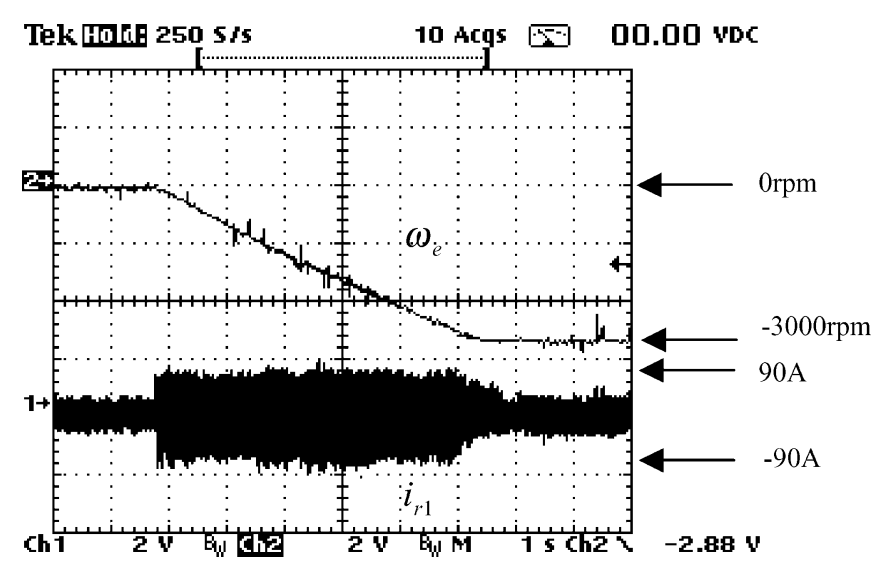

Fig. 14. Experimental waveform of rotor current during speed transient. 1 p.u. speed $=1500 \mathrm{r} / \mathrm{min}, 1$ p.u. current $=63.7 \mathrm{~A}(\mathrm{rms})$.

form when there is an instant frequency transition (from 47 to 15 $\mathrm{Hz}$ ). The smooth transition in current waveform ensures the reliability of the proposed controller. Figs. 16 and 17 present the experimentally generated frequency profiles of the stator- and the rotor-side inverters. They confirm the automatically generated stator frequency profile presented in Fig. 9. Fig. 18 shows the steady-state full-load motor currents.

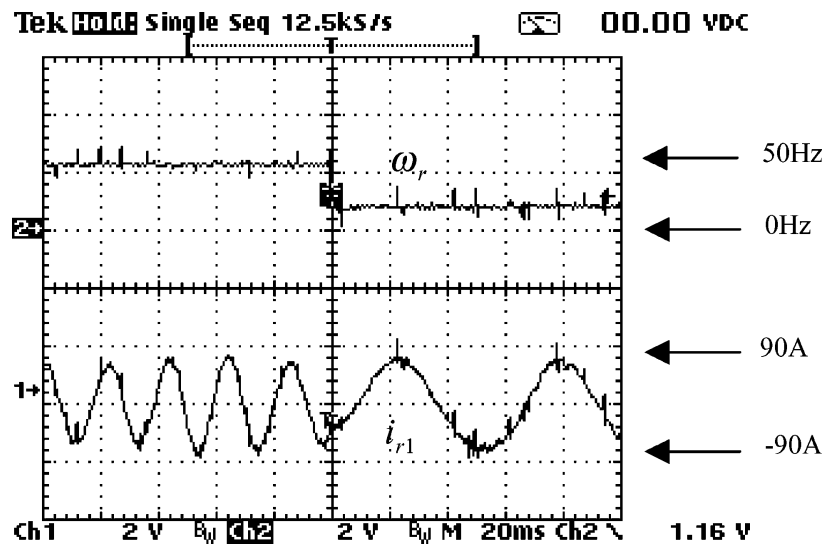

Fig. 15. Experimental waveform of sudden rotor frequency jump at full load. 1 p.u. frequency $=50 \mathrm{~Hz}, 1$ p.u. current $=63.7 \mathrm{~A}(\mathrm{rms})$.

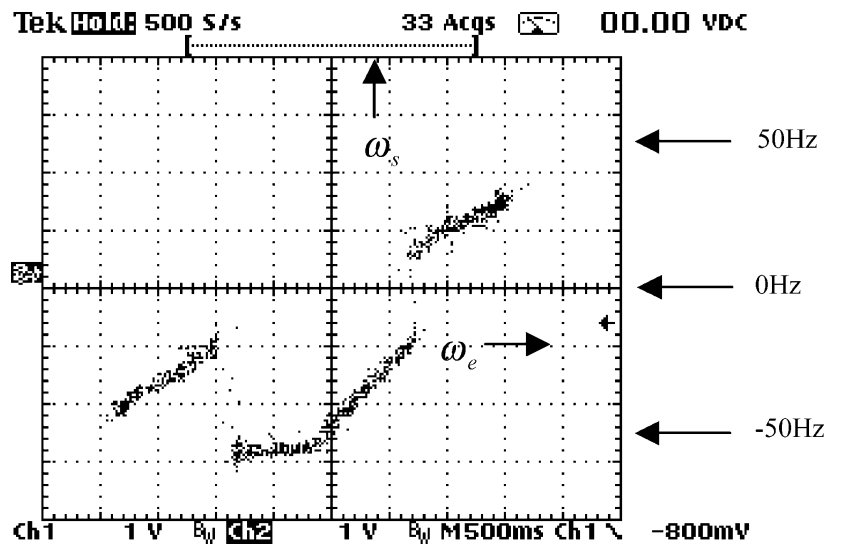

Fig. 16. Experimental phase plot of stator supply frequency versus rotor speed. 1 p.u. frequency $=50 \mathrm{~Hz}$.

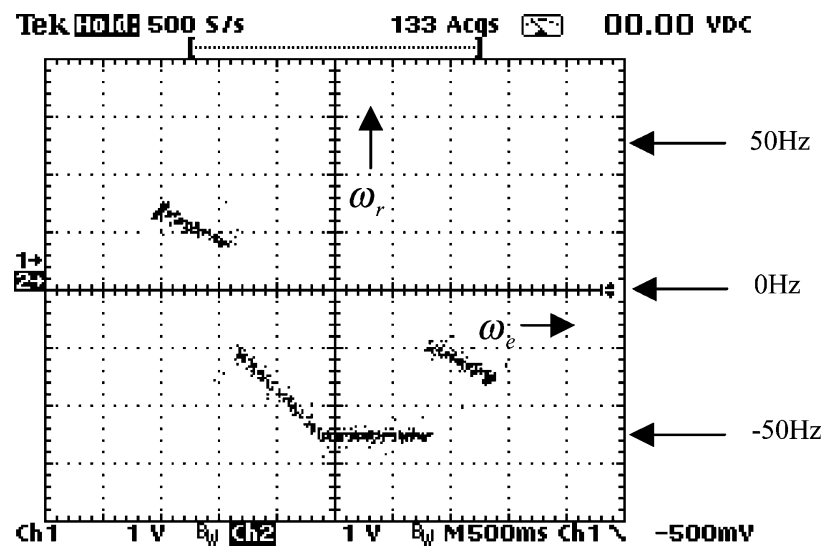

Fig. 17. Experimental phase plot of rotor supply frequency vs. rotor speed. 1 p.u. frequency $=50 \mathrm{~Hz}$.

\section{CONCLUSION}

A new control strategy has been proposed here for a doubly fed slip-ring induction motor. DTC is used on one side of the slip-ring induction machine. Direct frequency control is applied on the other side of the same machine. The resulting control is rugged and reliable. With the introduction of this controller, the doubly fed slip-ring induction machine runs up to double the 


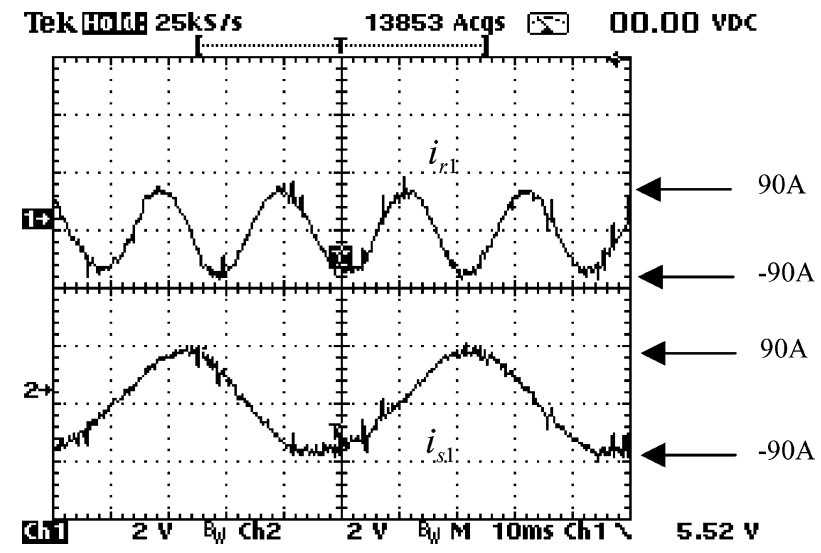

Fig. 18. Experimental waveform of steady state machine currents at full load. 1 p.u. current $=63.7 \mathrm{~A}(\mathrm{rms})$.

rated speed in either direction, without field-weakening operation. This, in turn, ensures full torque operation for the machine up to double the rated speed and, hence, double the rated power can be extracted from the machine. Because of direct torque and flux control on either side of the machine, there are no current transients in the machine during high dynamic operation.

The frequency profiles, proposed here, ensure that the frequency on either side of the doubly fed slip-ring induction machine never goes below $12 \mathrm{~Hz}$. Because of this feature, this control has very little dependence on machine parameters. Thus, the stator and the rotor voltage estimation errors due to the deadband time of the inverter and the inaccurate estimation of stator and rotor resistance drops have negligible effect on drive performances. Therefore, the reliability of the drive improves considerably. This feature also ensures that high torque can be obtained without any thermal stress on any of the inverter legs for any rotor speed.

The proposed controller estimates the rotor speed from the motor model and performs the control operation. Therefore, it eliminates the need for costly, unreliable position transducers and makes the drive more rugged. This sensorless method is very reliable even at zero rotor speed because of the rotor frequency profile proposed in this paper.

\section{APPENDIX \\ MACHINE PARAMETERS}

The parameters of the tested machine are as follows:

$$
\begin{aligned}
& \text { rated power-50 hp; } \\
& \text { rated frequency-50 } \\
& \text { rated speed- } 1475 \mathrm{r} / \\
& \text { stator voltage-400 } \\
& \text { rotor voltage-325 } \\
& \text { rated current-63.7 } \\
& R_{s}=0.137 \Omega \\
& R_{r}=0.1 \Omega ; \\
& L_{0}=40.1 \mathrm{mH} \\
& \sigma_{s}=0.033 \\
& \sigma_{r}=0.022
\end{aligned}
$$$$
\text { rated frequency }-50 \mathrm{~Hz} \text {; }
$$$$
\text { rated speed-1475 r/min; }
$$$$
\text { stator voltage-400 V; }
$$$$
\text { rotor voltage }-325 \mathrm{~V} \text {; }
$$$$
\text { rated current-63.7 } \mathrm{A} \text {; }
$$

\section{REFERENCES}

[1] W. Leonhard, Control of Electrical Drives. Berlin, Germany: Springer-Verlag, 1985

[2] R. Datta, "Rotor side control of grid-connected wound rotor induction machine and its application to wind power generation," Ph.D. dissertation, Dept. Elect. Eng., Indian Inst. Sci., Bangalore, India, 2000.

[3] Y. Kawabata, E. Ejiogu, and T. Kawabata, "Vector-controlled double-inverter-fed wound-rotor induction motor suitable for high-power drives," IEEE Trans. Ind. Applicat., vol. 35, pp. 1058-1066, Sept./Oct. 1999.

[4] I. Takahashi and T. Noguchi, "A new quick-response and high-efficiency control strategy of an induction motor," IEEE Trans. Ind. Applicat., vol. IA-22, pp. 820-827, Sept./Oct. 1986.

[5] T. G. Habetler and D. M. Divan, "Control strategies for direct torque control using discrete pulse modulation," IEEE Trans. Ind. Applicat., vol. 27, pp. 893-901, Sept./Oct. 1991.

[6] P. Tiitinen, "The next generation motor control method, DTC, direct torque control," in Proc. PEDES'96, New Delhi, India, 1996, pp. 37-43.

[7] G. Poddar and V. T. Ranganathan, "Sensorless field-oriented control for double-inverter-fed wound-rotor induction motor drive," IEEE Trans. Ind. Electron., vol. 51, pp. 1089-1096, Oct. 2004.

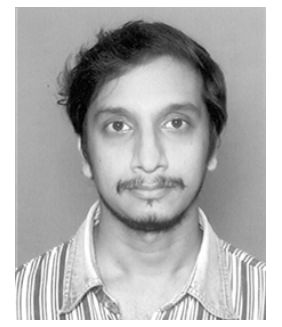

Gautam Poddar received the B.E. degree from Bengal Engineering College, Calcutta University, Calcutta, India, in 1992, the M.Tech. degree from the Indian Institute of Technology, Kharagpur, India, in 1994, and the Ph.D. degree from the Indian Institute of Science, Bangalore, India, in 2002, all in electrical engineering.

Since 1995, he has been with the Power Electronics Group, Electronics Research and Development Centre of India, Trivandrum, India, where he is working in the field of power electronics and drives. His fields of interest are control of high-power drives, sensorless control of ac motors, and active power filters.

Dr. Poddar was the recipient of an Indian National Academy of Engineers (INAE) Young Engineer Award in 2003.

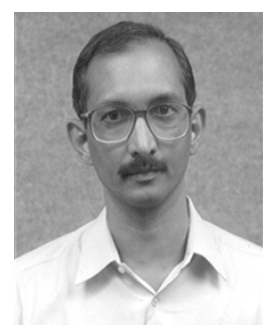

V. T. Ranganathan (M'86-SM'92) received the B.E. and M.E. degrees in electrical engineering from the Indian Institute of Science, Bangalore, India, and the Ph.D. degree from Concordia University, Montreal, QC, Canada.

In 1984, he joined the Electrical Engineering Department, Indian Institute of Science, where he is currently a Professor. His research interests are in the area of power electronics and motor drives. He has published several papers in the areas of vector control of ac drives, PWM techniques, split-phase induction motor drives, and slip-ring induction motor control. He is also a Consultant to industry in the above areas and has participated in a number of projects.

Prof. Ranganathan was the recipient of the Prize Paper Award of the Static Power Converter Committee of the IEEE Industry Applications Society, Tata Rao Prize of the Institution of Engineers, India, CV Raman Young Scientist Award, VASVIK Award, and Bimal Bose Award. He is a Fellow of the Indian National Academy of Engineering and Institution of Engineers, India. 